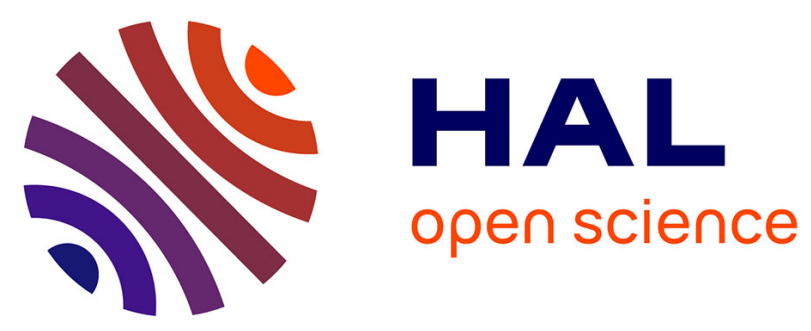

\title{
Strategies of Maximum Power Point Tracking for Sub-mW Benthic Microbial Fuel Cells
}

\author{
Armande Capitaine, Gaël Pillonnet, Bruno Allard
}

\section{To cite this version:}

Armande Capitaine, Gaël Pillonnet, Bruno Allard. Strategies of Maximum Power Point Tracking for Sub-mW Benthic Microbial Fuel Cells. Journal of Low Power Electronics, 2019, 15 (4), pp.351-360. 10.1166/jolpe.2019.1620 . hal-02526202

\section{HAL Id: hal-02526202 \\ https://hal.science/hal-02526202}

Submitted on 31 Mar 2020

HAL is a multi-disciplinary open access archive for the deposit and dissemination of scientific research documents, whether they are published or not. The documents may come from teaching and research institutions in France or abroad, or from public or private research centers.
L'archive ouverte pluridisciplinaire HAL, est destinée au dépôt et à la diffusion de documents scientifiques de niveau recherche, publiés ou non, émanant des établissements d'enseignement et de recherche français ou étrangers, des laboratoires publics ou privés. 


\title{
Strategies of Maximum Power Point Tracking for Sub-mW Benthic Microbial Fuel Cells
}

\author{
Armande Capitaine ${ }^{1,2, *}$, Gael Pillonnet ${ }^{1}$, and Bruno Allard ${ }^{2}$ \\ ${ }^{1}$ Université Grenoble Alpes, Commissariat à l'Energie Atomique et aux Energies Alternatives, Laboratoire d'Electronique et de Technologie \\ de l'Information, Département Architecture Conception et Logiciels Embarqués, Laboratoire de Gestion d'Energie Capteurs et Actionneurs, \\ F-38000 Grenoble, France \\ ${ }^{2}$ Université de Lyon, Institut National de Sciences Appliquées Lyon, Ampère, Unité Mixte de Recherche Centre National de la Recherche \\ Scientifique 5005, F-69621 Villeurbanne, France
}

(Received: 5 July 2019; Accepted: 14 October 2019)

\begin{abstract}
Benthic microbial fuel cells (MFCs) are promising alternatives to conventional batteries for powering underwater low-power sensors. Regarding performances (10's $\mu \mathrm{W}$ at 100 's $\mathrm{mV}$ for $\mathrm{cm}^{2}$-scale electrodes), an electrical interface is required to maximize the harvested energy and boost the voltage. Because the MFCs electrical behavior fluctuates, it is common to refer to maximum power point tracking (MPPT). Using a sub-mW flyback converter, this paper compares the benefit of different MPPT strategies: either by maximizing the energy at the converter input or at the converter output, or by fixing the MFC operating point at its nominal maximum power point. A practical flyback has been validated and experimentally tested for these MPPT options showing a gain in efficiency in certain configurations. The results allow determining a power budget for MPPT controllers that should not exceed this gain. Eventually, considering typical MFC fluctuations, avoiding any MPPT controller by fixing the converter operating parameters may offer better performances for sub-mW harvesters.
\end{abstract}

Keywords: Energy Harvesting, Flyback Converter, Low Power Electronics, Microbial Fuel Cell.

\section{INTRODUCTION}

Regarding the ever-increasing number of remote lowpower sensors, harvesting the energy from the surrounding environment is a pertinent solution to meet the energy needs but circumvent the usage of conventional batteries. On the one hand chemical batteries are still massively chosen despite their non-negligible cost, their limited lifetime and the pollution they are likely to produce. On the other hand, harvesting ambient energy is a promising alternative to power autonomously and indefinitely remote sensors in addition to process in an eco-friendly perspective. Solar, thermal and vibrational energies are currently studied and used in many applications. ${ }^{1}$

The microbial fuel cell (MFC) is a system harvesting the biochemical energy from a large range of organic substrates (compost, sewage, seafloor sediment...) thanks to the metabolism of embedded electro-active bacteria. ${ }^{2,3}$ Freshly developed and promoted in the 2000s, the benthic MFC, using sediment as the organic substrate, can now be

\footnotetext{
*Author to whom correspondence should be addressed

Email: armande.capitaine@u-bordeaux.fr
}

apprehended as a low-cost sustainable energy source for powering sensors at seafloor level where any other energies are absent. ${ }^{4,5}$ These sensors are essential for example to observe and predict the ocean behavior as well as natural risks e.g., tsunami...).

However, the maximum output power available from the benthic MFC is in the range of 10 's $\mu \mathrm{W}$ for $20-\mathrm{cm}^{2}$ scale electrodes (power density around $5 \mu \mathrm{W} / \mathrm{cm}^{2}$ ). The DC voltage is insufficient to power continuously the conventional electronic, e.g., up to $0.7 \mathrm{~V}$ in open-circuit condition. ${ }^{3}$ Therefore, a harvesting electrical interface is required to adapt and store the MFC energy to power a sensor, i.e., a power management unit (PMU) including a DC/DC converter extracting and shaping the energy prior to storage. The overall system is pictured in Figure 1. The DC/DC converter has a two-fold objective: (i) extract the maximum power from the MFC when operating at the maximum power point (MPP) and (ii) boost the voltage in the intermediate energy storage stage. Then the sensor switches between on-and off-state depending on the available energy. 


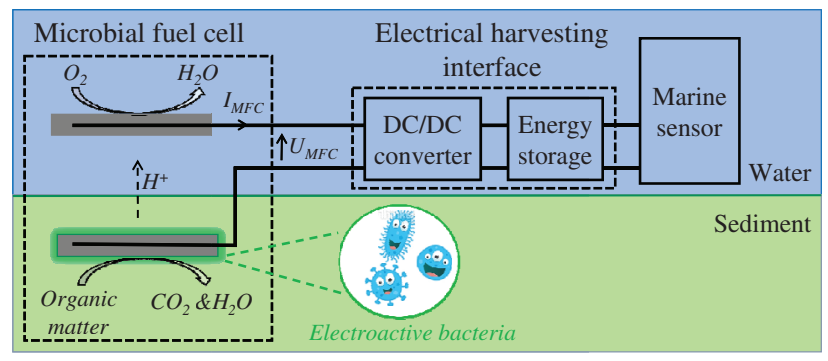

Fig. 1. Schematic of the MFC and the harvesting system.

The boost converter has widely been used for MFC energy harvesting ${ }^{6-10}$ because of its simplicity. Considering the direct combination of MFCs suffers from poor efficiency because of cell reversal, ${ }^{11-16}$ prefer using the flyback converter which allows a galvanic isolation and, when working in discontinuous conduction mode (DCM), allows selecting the MFC operating point independently of the output voltage.

Since the electrical behavior of the MFC is likely to vary under environmental fluctuations, a maximum power point tracking (MPPT) control unit is advised to constantly adapt the MFC operating point. Literature covers the ability of MPPT to extract the maximum power from MFCs. ${ }^{4}$ Few MPPT schemes have been implanted into power management units dedicated to upper-mW MFCs leading to low efficiencies $\left(30 \%,{ }^{7} 35.9 \%{ }^{8}\right.$ and up to $\left.50 \%,{ }^{13}\right)$ but not in the sub-mW context. At 10 's $\mu \mathrm{W}$ power extraction (two decades lower than in literature for MFC), every $\mu \mathrm{W}$ are precious and any losses in the converter mean a drastic degradation of the efficiency. Therefore, regarding the MFCs electrical variations (especially on the seafloor where parameters are quite stable) and the low power range $(10$ 's $\mu \mathrm{W})$, dynamically tracking the MPP is not necessarily relevant. Moreover, no study has yet focused the ability to maximize the power at the output of the converter associated to the MFC. Indeed, tracking the MPP at the MFC output i.e., at the converter input modifies the converter efficiency which will impact the end-to-end efficiency.

This paper proposes to compare the harvesting system performances when adopting three MPPT strategies for sub-mW benthic MFCs: (i) the maximum extracted energy strategy (MEES) which maximizes the power at the converter input, (ii) the maximum harvested energy strategy (MHES) which maximizes the power at the output of the converter and (iii) the fixed operating point strategy (FOPS) which fixes the converter parameters whatever the MFC electrical variations. It is worth noticing that MPPT strategy the most commonly used in MFC literature is the one we call MEES. The results will then allow defining a power budget for the MEES and MHES control units. This study uses a flyback converter topology already validated in Ref. [14] and optimized for the specifications
Table I. Converter specifications.

\begin{tabular}{lc}
\hline Parameter & \\
\hline Input voltage & $0.3 \mathrm{~V}$ \\
Input power & $90 \mu \mathrm{W}$ \\
Output regulated voltage & $2 \mathrm{~V}$ \\
Operating frequency range & Few Hz to few kHz \\
Input voltage ripple & $<0.1 \mathrm{~V}$ \\
\hline
\end{tabular}

presented in Table I. Possible converter topologies as electrical interface for MFCs have been discussed in Ref. [22] and the proposed flyback offer the most satisfying tradeoff.

Section 2 presents the MFC design. Section 3 introduces the flyback converter design at 10 th $\mu \mathrm{W}$ and discusses the impact of the MFC electrical fluctuations on the converter efficiency when using MEES. Then regarding the MFC fluctuations, the power budgets for the MEES and MHES control unit are evaluated in Section 4, by comparing the converter end-to-end efficiency obtained with fixed parameters (FOPS) to the ones obtained with adapting the parameters according to MEES and MHES strategies. Section 4 discusses the relevance of using a control unit (i.e., tracking a working point) instead of initially setting the converter parameters. This work has been carried out using a flyback converter in Discontinuous-ConductionMode $(\mathrm{DCM})^{14}$ in a sub-mW power range. The results are supported with electrical simulations of the system to allow differentiating the extraction efficiency from the conversion efficiency and determining the losses' contributors using the three MPPT strategies. This paper is the first to compare three MPPT strategies for sub-mW MFCs and to determine the power budget of the control unit for MEES and MHES.

\section{BENTHIC MFC}

A schematic diagram of this particular MFC is shown in Figure 1. Bacteria catalyze the oxidation of the organic substrate at the anode while the oxygen dissolved in fresh water is reduced at the cathode, inducing a transfer of electrons and thus electrical energy generation. ${ }^{2}$ Marine sediment is chosen for lab-scale experiment as the anaerobic bacterial medium and as "fuel" (organic matter) in which thick graphite felt (RVG4000, Mersen) anode of $20 \mathrm{~cm}^{2} \times 1.2 \mathrm{~cm}$ is buried. An identical electrode is placed in seawater working with an air bubbling system to favor oxygenation. Electrons are collected from the electrodes by $\varnothing 0.75 \mathrm{~mm}$ insulated titanium wires. Although titanium is not the best available electrical conductor, it was selected because of its high resistance to corrosion $\left(\mathrm{TiO}_{2}\right)$ but lesser cost than platinum. Three MFCs are elaborated using sediments collected at the Plage du Gaou, a beach close to a nature conservation area near the Mediterranean sea $\left(43^{\circ} 04^{\prime} 13.7^{\prime \prime} \mathrm{N}-5^{\circ} 47^{\prime} 36.6^{\prime \prime} \mathrm{E}\right)$. No additional substrate (e.g., acetate) was added for the start-up phase (around one 


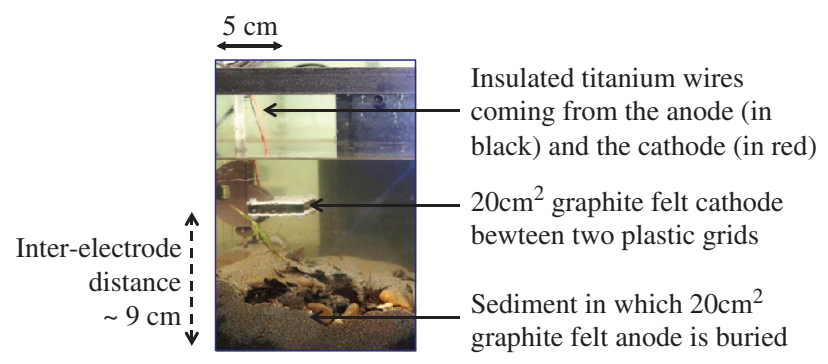

Fig. 2. Lab-scale benthic MFC.

month) or during steady-state operation in order to mimic natural conditions. Figure 2 shows a lab-scale MFC. The price of the material for each fuel cell is of the order of one euro, so many MFCs could be scattered in oceans and lakes, and a large matrix of self-sufficient sensor nodes could thus be deployed.

\subsection{MFC Characterization and Modeling}

The static behavior of each MFC is given in Figure 3. The $U-I$ curves are obtained by first measuring the opencircuit voltage $U_{\mathrm{OC}}$, then decreasing step-by-step the voltage $U$ by $50 \mathrm{mV}$ while measuring $I$. The current always starts with a peak value and then slowly decreases because of internal capacitive effects. ${ }^{3}$ It is recorded in steadystate, which occurs after one hour. Each characteristic can be roughly fitted by a straight line and modeled as a voltage source $V_{\mathrm{S}}$ and a series resistance $R_{\mathrm{S}}$ (Fig. 3) as it is often done for solar, thermal or bio fuel cell harvesters when operating close to their maximum power point (MPP). The MFC as in Figure 2 is modeled with $V_{\mathrm{S}}=0.6 \mathrm{~V}$ and $R_{\mathrm{S}}=1 \mathrm{k} \Omega$ what represents a maximum output power $P_{\mathrm{MPP}}$ of $90 \mu \mathrm{W} @ 0.3 \mathrm{~V}$. The equivalent characterization is represented by the blue dotted curve in Figure 3.

Identifying the two parameters $\left(V_{\mathrm{S}}, R_{\mathrm{S}}\right)$ in the MFC model is a crucial step to determine the impedance value
$R_{\mathrm{IN}}$ of the harvesting interface and optimize the power extraction from this MFC. In fact, the extracted power is maximized when $R_{\mathrm{IN}}$ is equal to $R_{\mathrm{S}}{ }^{2}$ and is expressed at MPP as:

$$
P_{\mathrm{MPP}}=\frac{V_{\mathrm{S}}^{2}}{4 R_{\mathrm{S}}}
$$

Moreover, the MFC performances depend on the environmental conditions (temperature, pressure...) and the MFC model parameters change. According to Figure 3, for identically designed MFCs, $V_{\mathrm{S}}$ is likely to vary from $0.6 \mathrm{~V}$ to more than $0.7 \mathrm{~V}$ and $R_{\mathrm{S}}$ from $500 \Omega$ to more than $3 \mathrm{k} \Omega$. Experimental results on these same MFCs at different time have shown that the two latter parameters typically stay in the range of $[0.4 \mathrm{~V} ; 0.8 \mathrm{~V}]$ and $[100 \Omega ; 5 \mathrm{k} \Omega]$ respectively. Thus, the MPP should be regularly monitored to allow a dynamic impedance matching of $R_{\mathrm{IN}}$ and $R_{\mathrm{S}}$. We call this commonly used MPPT strategy: maximum extracted energy strategy (MEES).

\subsection{Harvesting Electrical Interface}

A harvesting electrical interface is required to (i) extract energy from the MFC (for instance with MEES), (ii) stepup the voltage $V_{\text {IN }}$ to a minimum voltage $V_{\text {OUT }}$ required to supply the sensor and (iii) store the harvested energy in a capacitance $C_{\text {OUT }}$ to deliver it intermittently to the sensor. The harvesting interface is commonly realized with a DC/DC converter. The global system is represented in Figure 4 (top).

We define three values of efficiency:

- The extraction efficiency $\eta_{\text {EXTR }}$ : the ratio between $P_{\mathrm{IN}}$ and the maximum power the MFC can deliver $P_{\mathrm{MPP}}$ (Fig. 4).

- The conversion efficiency $\eta_{\mathrm{CONV}}$ : the ratio between the converter output power $P_{\text {OUT }}$ and its input power $P_{\mathrm{IN}}$.

- The "end-to-end efficiency" $\eta_{\text {TOT }}$ : the product of $\eta_{\text {EXTR }}$ and $\eta_{\mathrm{CONV}}$, is the efficiency value to maximize in order to increase the power delivered to the sensor (Fig. 4).

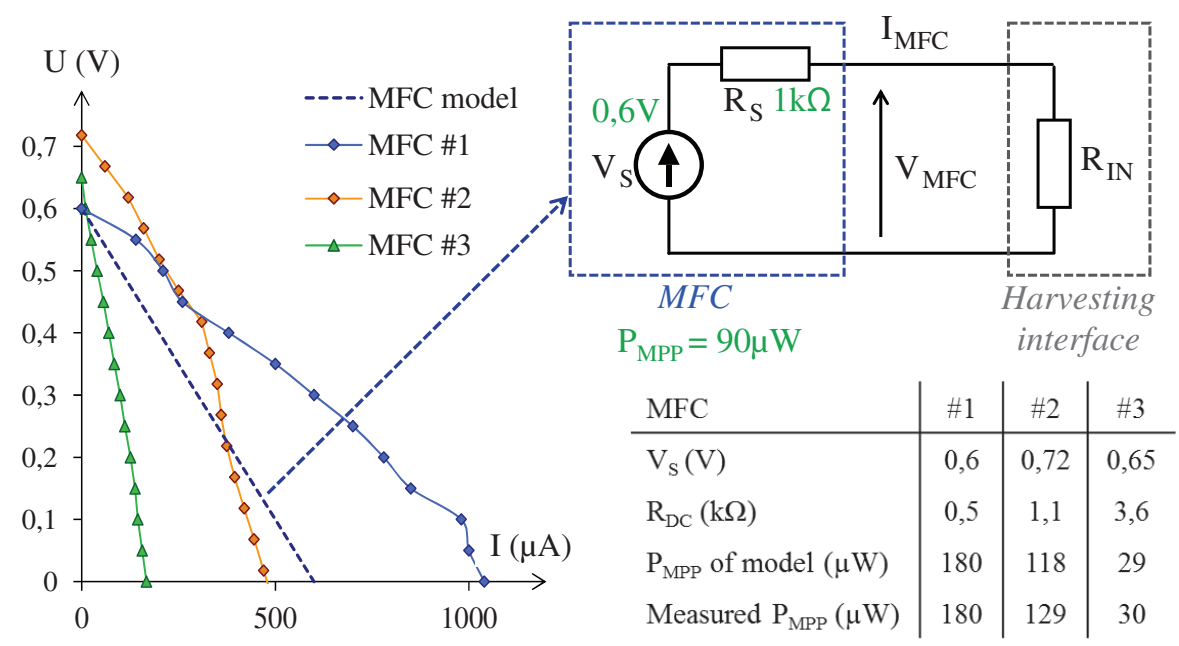

Fig. 3. Characteristics of lab-scale benthic MFCs and identified electrical model. 


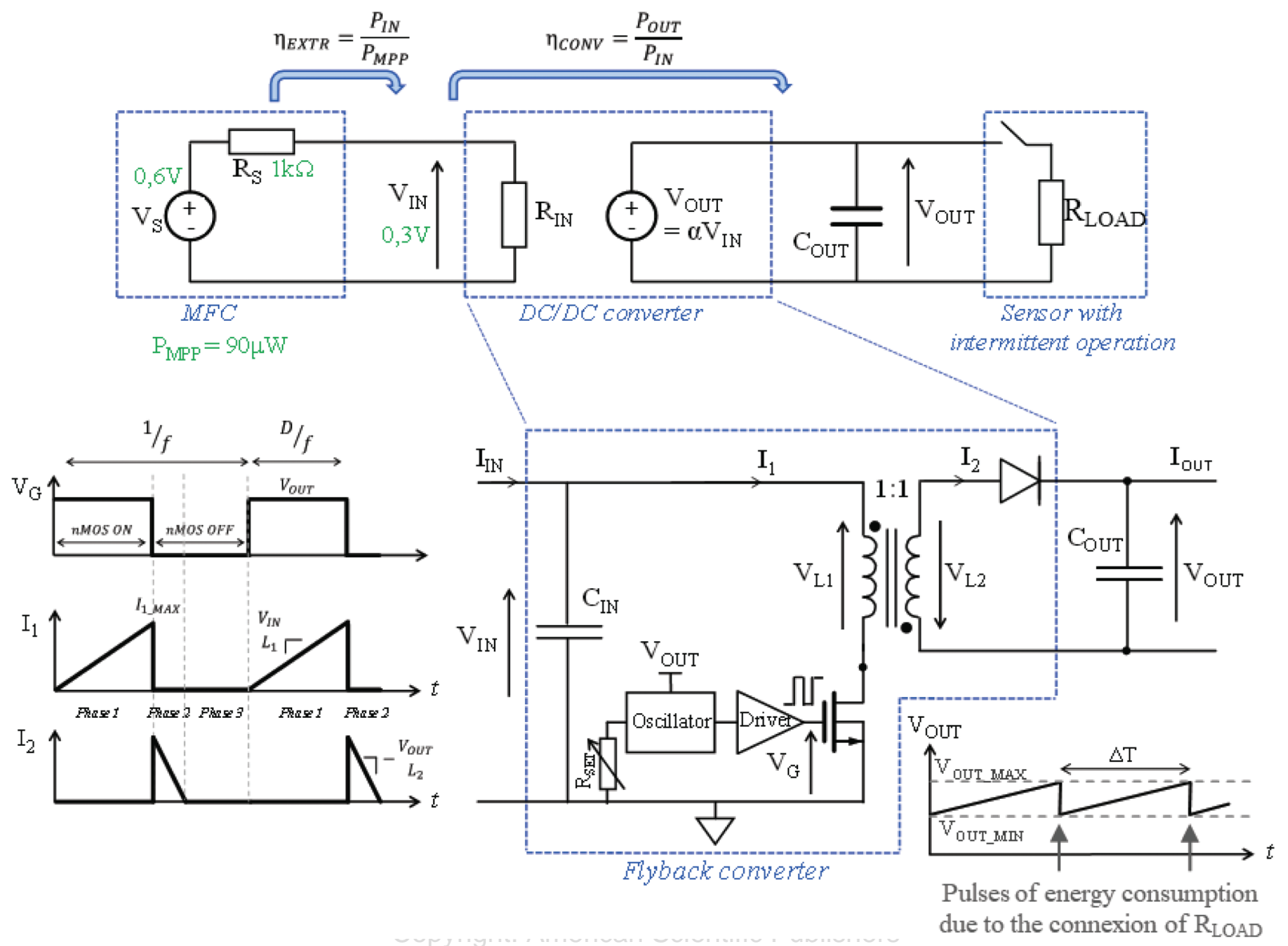

Fig. 4. Schematic of the overall circuit including the MFC model, the DC/DC converter and the intermittent sensor (top). Flyback converter in DCM operation (bottom).

Regarding low power range at stake, maximizing $\eta_{\text {EXTR }}$ without considering $\eta_{\text {CONV }}$ may lead to a low $\eta_{\text {TOT }}$. That is why using MEES is not straight-forward for sub-mW MFCs.

\section{DC-DC CONVERTER DESIGN}

This section presents the converter design for a maximum power extraction of $100 \mu \mathrm{W}$, which is representative of the average behavior of our lab-made MFCs (Fig. 3).

\subsection{Topology Choice and Design Trade-Off}

The flyback converter operating in DCM is selected because its input impedance $R_{\mathrm{IN}}$ can be dynamically adapted to $R_{\mathrm{S}}$ by controlling the switching frequency $f$, without impacting the voltage gain, $\alpha$ (Fig. 4). Therefore, MEES can be handled whatever the output voltage $V_{\text {OUT }}$. Moreover, the flyback topology offers a galvanic isolation between input and output, which is required when considering parallel/series configuration of MFCs or multiple MFCs with shared anodes. ${ }^{15,17}$

The flyback structure is shown in Figure 4. DCM operation covers three topologies per switching period.
In phase 1 , the MOSFET is turned-on with $50 \%$ duty cycle and the current in the primary inductance $I_{1}$ increases quasi-linearly until reaching $I_{1 \_ \text {MAX }}(2)$. The current in the secondary side of the transformer, $I_{2}$, is null due to the diode. When the MOSFET is turned-off, the magnetic energy $E_{1}$ stored in the primary inductance is transferred to the secondary inductance (3). Considering a conversion ratio of 1:1 for the coupled inductances (secondary inductance equal to $L_{1}$ ), the output current $I_{2}$ is equal to $I_{1, \operatorname{MAX}}$ at the beginning of phase 2 and decreases quasi-linearly. The last part in the switching period starts when $I_{2}$ reaches zero until the end of the switching period. A self-powered oscillator is used to generate the gate signal of the transistor. This oscillator is supplied with the output voltage in order to ensure an autonomous operation once the flyback is started. A bypass input capacitance $C_{\mathrm{IN}}$ is introduced to obtain a quasi-constant input voltage, $V_{\mathrm{IN}}$, and avoid current ripple. At the output, the energy is stored in a capacitance $C_{\text {OUT }}$ and is intermittently delivered to the sensor with an adaptable period $\Delta \mathrm{T}$ as shown in Figure 4, making the output voltage oscillates between two values, $V_{\text {OUt_max }}$ and $V_{\text {OUt_min }}$, where the latter must be higher than the minimal voltage required by the sensor. When the 
sensor is in idle mode, DC energy from the harvester is stored in $C_{\text {OUT }}$. If the harvested power is superior to the idle power of the sensor, $V_{\text {OUT }}$ increases. When available energy is sufficient (after a time $\Delta T$ ), the sensor wakes up and runs its function (records the temperature and the acceleration as well as wirelessly transmitting the information) consuming an energy $E_{\text {SENSOR }}$ from $C_{\text {OUT }}$, hence decreasing the voltage to $V_{\text {OUT_MIN }}$.

$$
I_{1 \_\mathrm{MAX}}=\frac{V_{\mathrm{IN}} D}{L_{1} f}
$$

\subsection{Operation at MPP}

The flyback impedance $R_{\mathrm{IN}}$ can be expressed as Ref. [3]. In order to extract the maximum power $P_{\mathrm{MPP}}$ from the MFC, we need to match this impedance to $R_{\mathrm{S}}$, equal to $1 \mathrm{k} \Omega$ in the typical case, i.e., the product $L_{1} \cdot f$ must be fixed. Assuming $D$ and $L_{1}$ fixed, the MEES is handled by varying the frequency accordingly to the fluctuations of the MFC impedance $R_{\mathrm{S}}$.

$$
R_{\mathrm{IN}}=\frac{2 L_{1} f}{D^{2}}
$$

\subsection{Contributors to Losses in the Flyback}

The flyback topology includes different components that create losses: MOSFET, diode, coupled inductances and the oscillator. The MOSFET presents an on-state resistance $R_{\mathrm{ON}}$ causing conduction losses during phase 1 and internal capacitances $C_{\mathrm{OSS}}$ and $C_{\mathrm{G}}$ causing switching losses. The diode presents a threshold voltage $V_{\mathrm{D}}$ causing conduction losses during phase 2 and a parasitic capacitance $C_{\mathrm{D}}$. The oscillator presents internal power consumption $P_{\text {OSC }}$ depending on the frequency. Eventually the coupled inductances induce losses due to copper resistance, the leakage current, the inter-winding capacitances and hysteresis in the magnetic core. A trade-off between these losses is detailed in Ref. [14] to maximize the conversion efficiency for the targeted power level. Particular attention has to be paid to the coupled inductors choice to limit switching losses. Using the experimentally verified results in Ref. [14], the following off-the-shell components were chosen.

\subsection{Off-the-Shelf Components Choice}

Reducing MOSFET channel resistance $R_{\mathrm{ON}}$ (increasing the drain-source channel width) increases the internal capacitance $C_{\text {OSS }}$. N-channel MOSFET FDV301N (Fairchild Semiconductor) was confirmed to be a good tradeoff for sub-mW operation. Its threshold gate voltage is $1 \mathrm{~V}$ with a capacitance $C_{\mathrm{OSS}}$ in the order of $90 \mathrm{pF}$. The device features $R_{\mathrm{ON}}$ of $3.5 \Omega$ and a total gate charge $\mathrm{Qg}$ of $80 \mathrm{pC}$ when operating with $V_{\mathrm{G}}$ equal to $2 \mathrm{~V}$. BAT54 diode (Vishay Semiconductors) has been chosen because of its threshold voltage lower than $0.3 \mathrm{~V}$ and low parasitic capacitance $C_{\mathrm{D}}$ of $10 \mathrm{pF}$, thus minimizing the conduction losses in the secondary side of the flyback topology as well as the switching losses. The tunable oscillator TS3004 (Silicon Labs) was chosen because of a very low power consumption (order of $\mu \mathrm{W}$ ) while presenting adequate operating conditions regarding its supply voltage and frequency range $(2 \mathrm{~V}$ and $[5 \mathrm{mHz} ; 300 \mathrm{kHz}])$. The operating frequency is set with an external resistor $R_{\mathrm{SET}}$ (represented in Fig. 4). Eventually, we selected coupled inductances from muRata (78601/9C) presenting a primary inductance $L_{1}$ of $18 \mathrm{mH}$, a conversion ratio of 1 and a saturation current $I_{\mathrm{SAT}}$ of $4 \mathrm{~mA}$. According to Ref. [14], this design allows a maximum end-to-end efficiency of $70 \%$ at $90 \mu \mathrm{W}$.

\subsection{Parameters' Sizing}

Assuming the coupled inductances conversion ratio equal to unity, the duty cycle D has to be minimized to keep the flyback in DCM. ${ }^{18}$ The duty cycle should also be maximized to avoid an important value of $I_{1, \operatorname{MAX}}(2)$ that may drive the transformer to saturation and also induce large conduction losses in the switch. Setting the duty cycle D to 0.5 is a fair tradeoff in a first step. The frequency $f$ is fixed according to (3) to respect the MPP condition. For $R_{\mathrm{S}}$ equal to $1 \mathrm{k} \Omega, f$ is set to $6.9 \mathrm{kHz}$. Eventually, the input capacitance $C_{\mathrm{IN}}$ is used to maintain a DC voltage at the input of the flyback. Its value has to be sufficiently important in order to insure a negligible input voltage ripple $\Delta V_{\mathrm{IN}} \cdot \Delta V_{\mathrm{IN}}$ is set to $1 \%$ of $V_{\mathrm{IN}}$ what corresponds to an input capacitance of $6.3 \mu \mathrm{F}$ when operating at $6.9 \mathrm{kHz}$. Moreover, ${ }^{19}$ shows that adding this capacitance at the converter input lowers significantly the dynamic losses inside the MFC. With our capacitance value, they become negligible (less than $0.1 \%$ of the extracted power).

\section{ANALYSIS OF EXTRACTION STRATEGIES}

\subsection{Simulation and Experimental Setups}

In order to differentiate the loss contributors, a full model of the flyback is simulated in SPICE environment, using the components' models given by manufacturers (MOSFET, diode, oscillator) or experimentally characterized (coupled inductances). ${ }^{14}$

In the following simulation and experimental studies, we chose to model the MFC with the Thevenin circuit determined in Section 2.2. The average sensor power consumption is modeled by a voltage source of $2 \mathrm{~V}$, the average value around which the sensor will be set to operate. Considering the output capacitance $C_{\text {OUT }}$ sufficiently large ( $C_{\text {OUT }}$ is considered as an infinite storage element), we assume the oscillations $\Delta V_{\text {OUT }}$ can be neglected and will have no impact on the analysis.

A flyback is designed on a PCB board to be experimentally tested against three MPPT strategies. The voltages $V_{\mathrm{S}}$ and $V_{\text {OUT }}$ are generated by voltage sources (Series 2400, Keithley) with a $\mu \mathrm{W}$-precise reading. $P_{\text {OUT }}$ will be deduced from the latter reading (adding a decoupling capacitance 
to average $P_{\text {OUT }}$ ) while $P_{\text {IN }}$ will be deduced from $V_{\text {IN }}$ measured with an oscilloscope (MSO2000B Series, Tektronix). Figure 5 presents the experimental results that will be discussed in the following section.

\subsection{MEES Study}

As explained in Section 2.2, the environmental variations induce a dynamic change in the MFC model. In order to apprehend the relevance of MEES regarding the fluctuations in the MFC, we analyze experimentally the conversion efficiency dependence on the two parameters $V_{\mathrm{S}}$ and $R_{\mathrm{S}}$. It is worth noticing that the fluctuations in the MFC are far slower than the dynamics of the converter. First, considering $R_{\mathrm{S}}$ fixed to $1 \mathrm{k} \Omega, V_{\mathrm{S}}$ variations in the range $[0.4 \mathrm{~V} ; 0.8 \mathrm{~V}]$ impacts the efficiencies as displayed in Figure 5(a). The frequency $f$ is set manually to $6.9 \mathrm{kHz}$ to operate at MPP (3). It is worth noticing that the input power $P_{\mathrm{IN}}$ at MPP is proportional to the square of $V_{\mathrm{S}}$, i.e., a decrease in $V_{\mathrm{S}}$ induces a decrease in $P_{\mathrm{IN}}$. We first observe that $V_{\mathrm{S}}$ does not influence $\eta_{\text {EXTR }}$. It is coherent since $R_{\mathrm{S}}$ value is fixed and the impedance matching is still respected. However, a decrease in $V_{\mathrm{S}}$, i.e., decrease in $P_{\mathrm{IN}}$, creates a drop of $\eta_{\mathrm{CONV}}$. Although decreasing $P_{\mathrm{IN}}$ induces a decrease in the static losses (essentially due to the diode and the resistive parasitic elements of the coupled inductances). The switching losses remain approximately constant because the frequency is fixed (essentially due to the MOSFET, the oscillator and the capacitive parasitic elements of the coupled inductances), so they become significant regarding $P_{\mathrm{IN}}$. On the other hand, while increasing $V_{\mathrm{S}}$, i.e., increasing $P_{\mathrm{IN}}$, the static losses become predominant and $\eta_{\text {CONV }}$ reaches a plateau. The pie charts in Figure 5(a) represent the breakdown of losses in the flyback using simulation for the extreme cases. While increasing $V_{\mathrm{S}}$ from $0.4 \mathrm{~V}$ to $0.8 \mathrm{~V}$, the diode losses (from 19\% to 38\%) overcome the MOSFET and oscillator ones (from 32\% to $17 \%$ ). In both cases the coupled inductances remain the major contributors to losses.

The MFC resistance $R_{\mathrm{S}}$ is also likely to vary depending on the environmental conditions. The impact of these variations on $\eta_{\text {CONV }}$ is analyzed through simulation with $R_{\mathrm{S}}$ ranging from $100 \Omega$ to $5 \mathrm{k} \Omega$ (cf. Section 2.2). For each resistance, $f$ is manually adapted according to (3) in order to stay in the MPP conditions. The results are displayed in Figure 5(b). The abscissa axis represents $R_{\mathrm{S}}$ normalized by $1 \mathrm{k} \Omega$ (the nominal resistance used to design the flyback). When doubling $R_{\mathrm{S}}, \eta_{\mathrm{CONV}}$ varies from $68 \%$ to $56 \%$, and when increasing the resistance even more, the efficiency drops logarithmically because the frequency is incremented according to MEES, what induces a drastic increase in the switching losses. Therefore, even if $\eta_{\text {EXTR }}$ is set near unity, the end-to-end efficiency $\eta_{\text {TOT }}$ drops because of the losses in the flyback. On the contrary, when decreasing the resistance, a decrease in the switching losses would be expected and thus an increase in $\eta_{\mathrm{CONV}}$.
However, $\eta_{\text {CONV }}$ slightly decreases from $68 \%$ to $62 \%$ when dividing the resistance value by two. This decrease gets more severe with lower resistance $\left(\eta_{\text {CONV }}\right.$ reaches $20 \%$ when dividing the resistance by 10). This is a consequence of the saturation in the coupled inductances as illustrated in Figure 5(c) as $I_{1 \_ \text {MAX }}$ follows Eq. (2). This graph represents the evolution of the theoretical maximum input current $I_{1, \mathrm{MAX}}$ regarding the change in $R_{\mathrm{S}}$ when respecting MEES. A decrease in $R_{\mathrm{S}}$ induces an increase in $I_{1, \text { MAX }}$ converging to the saturation current $I_{\mathrm{SAT}}$ of the coupled inductances. When getting closer to $I_{\mathrm{SAT}}$, the hysteresis losses increase. When exceeding $I_{\text {SAT }}$ value, the increase in the hysteresis losses, i.e., decrease in $\eta_{\mathrm{CONV}}$, are conjugated with a decrease in $\eta_{\text {EXTR }}$ as $L_{1}$ is not at its nominal value. This decrease is correlated to the coupled inductances saturation: the measured primary inductance $L_{1}$ does not reflect the real operation of the coupled inductances and (3) is not satisfied with respect to MEES. To keep an end-toend efficiency $\eta_{\text {тот }}$ higher than $55 \%$, the MFC internal resistance should stay in the range [200 $\Omega ; 2 \mathrm{k} \Omega$ ]. An optimization of the coupled inductances may extend the latter range. Particularly selecting a magnetic device with a higher $I_{\mathrm{SAT}}$, the phenomena may be avoided (however, increasing $I_{\text {SAT }}$ requires larger coupled inductances). The switching losses due to hysteresis may be reduced and the efficiency drop may be attenuated when $R_{\mathrm{S}}$ increases. In the same way, increasing the duty cycle D (not too much to stay in DCM) may attenuate the saturation.

\subsection{Comparison of MEES and MHES}

Relevance of MEES is discussed with comparison to another strategy called MHES. The two strategies are described in Table II. The end-to-end efficiencies $\eta_{\text {Tот }}$ of each strategy regarding the MFC internal resistance variations are pictured in Figure 5(d). It is worth noticing that for MEES and MHES, the conditions are installed by "manually" adapting the operating frequency with the oscillator resistance $R_{\mathrm{SET}}$. In a final step, a control unit should be used to maintain the strategy dynamically. Since MHES requires the same control circuit as MEES (except that the controlled power is at the output and not at the input of the converter), we can assume that the latter controller power losses are identical. That is why we can consider that comparing MEES and MHES efficiencies without the suggested control unit will give appropriate conclusions.

MHES presents the best efficiency values, what is coherent since the operating frequency values are chosen to get the maximum output power, $P_{\text {Out_MAX }}$. These frequency values are compared to the ones used in MEES in Figure 5(e). In the range close to the initial MPP $\left(R_{\mathrm{S}}=1 \mathrm{k} \Omega\right.$, i.e., $X$ axis at 1$)$, the frequency values are identical and the MEES allows reaching $P_{\text {OUt_MAx }}$. When the MFC internal resistance exceeds two times the initial value, MHES needs to operate with a lower frequency than 
(a)

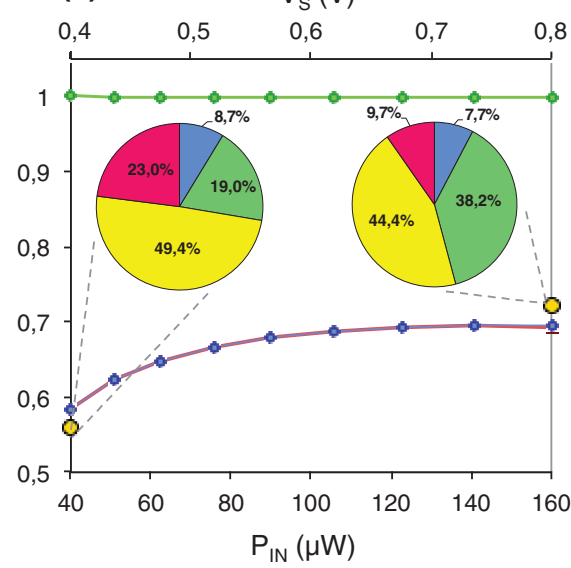

(c)

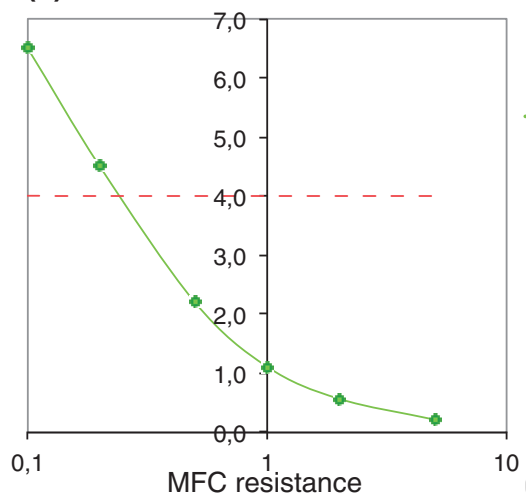

normalized relatively to $R_{S}=1 \mathrm{k} \Omega$

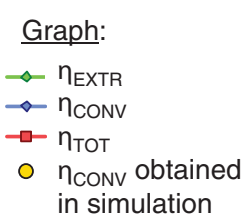

Pie charts:

口 MOSFET

$\square$ Diode

$\square$ Coupled inductances

- Oscillator (b)

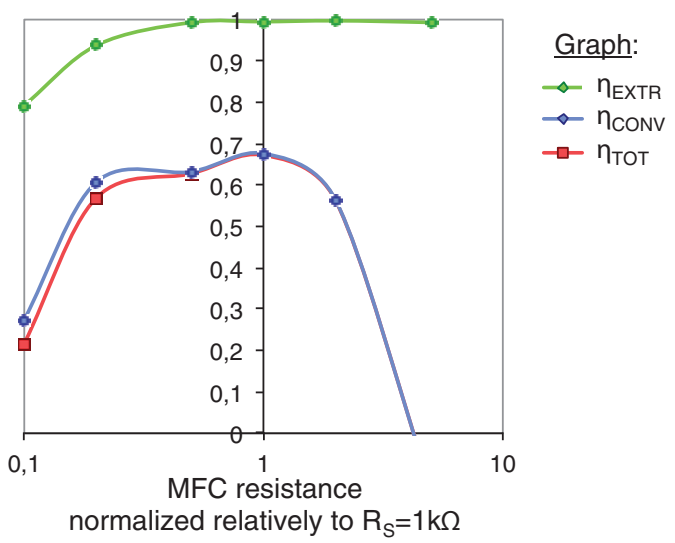

(d)

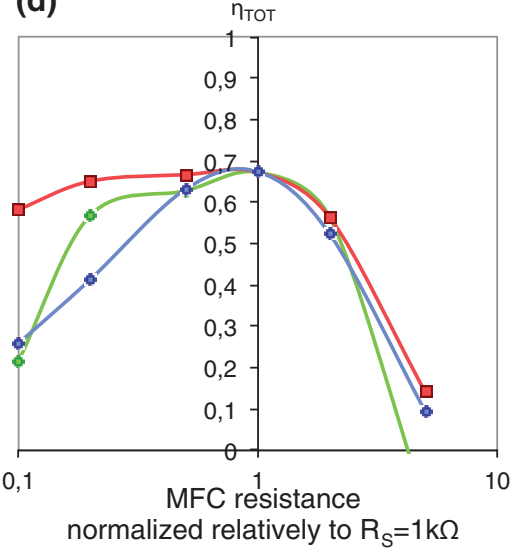

Graph:

$\rightarrow$ MEES

$\rightarrow$ MHES

$\rightarrow$ FOPS

normalized relatively to $R_{S}=1 \mathrm{k} \Omega$ (e) Operating frequency $\mathrm{f}(\mathrm{Hz})$



Graph:

current of the

flyback $I_{1}$ MAX (mA)

\section{- - Saturation} current of the coupled inductances \#2 $\mathrm{I}_{\mathrm{SAT}}(\mathrm{mA})$

1.149

(f)

Graph:

$\rightarrow$ MEES

Fig. 5. Experimental results from the system in Figure 4. (a) VS and (b) RS influence on the flyback efficiency with MEES. (c) $R_{\mathrm{S}}$ influence on $I_{1, \text { MAX }}$ with MEES. (d) $\eta_{\text {TOT }}$ using MEES, MHES and FOPS and (e) frequency values used with MEES and MHES. (f) Efficiencies $\eta_{\text {EXTR }}$ and $\eta_{\text {CONV }}$ with MEES and FOPS.

with MEES, reducing the switching losses and increasing $\eta_{\mathrm{CONV}}$, even if this means decreasing $\eta_{\mathrm{EXTR}}$. On the contrary when the MFC internal resistance is reduced more than by half, operation requires higher frequency values in order to avoid the magnetic core saturation issue causing high hysteresis losses and also to improve $\eta_{\text {EXTR }}$ with operation closer to MPP. Therefore, MHES is a more efficient strategy to harvest the maximum power at the output of the flyback than MEES.

Consequently, MEES may not be the best strategy regarding our target. MHES requires the same control circuitry and allows harvest more energy. 
Table II. Strategies of MPPT.

\begin{tabular}{|c|c|c|c|}
\hline \multirow[b]{2}{*}{ Strategy } & \multirow[b]{2}{*}{ Description } & \multicolumn{2}{|c|}{ Condition on } \\
\hline & & Efficiencies & Frequency $f$ \\
\hline MEES & $\begin{array}{l}\text { The operating point of } \\
\text { the flyback is set so } \\
\text { as to reach the } \\
\text { MFC MPP }\end{array}$ & $\begin{array}{l}\max \left(\eta_{\text {EXTR }}\right) \\
\quad \forall R_{\mathrm{S}}\end{array}$ & $\begin{array}{l}f \text { is tuned to respect } \\
\text { MPP condition (3) }\end{array}$ \\
\hline MHES & $\begin{array}{l}\text { The output power of } \\
\text { the flyback is set to } \\
\text { its maximum value }\end{array}$ & $\begin{array}{l}\max \left(\eta_{\mathrm{TOT}}\right) \\
\quad \forall R_{\mathrm{S}}\end{array}$ & $\begin{array}{l}f \text { is tuned to obtain } \\
\text { the maximum } \\
\text { power at the output }\end{array}$ \\
\hline FOPS & $\begin{array}{l}\text { The operating point of } \\
\text { the flyback is fixed } \\
\text { to the nominal MFC } \\
\text { MPP condition }\end{array}$ & $\begin{array}{l}\max \\
\quad\left(\eta_{\mathrm{EXTR}}\right) @ \\
\quad R_{\mathrm{S}}\left(t_{0}\right)\end{array}$ & $\begin{array}{l}f \text { is fixed and initially } \\
\text { adapted to } \\
R_{\mathrm{S}}\left(t_{0}\right)=1 \mathrm{k} \Omega\end{array}$ \\
\hline
\end{tabular}

\subsection{FOPS Benefit}

We now study the case where the converter operates without any tracking (operating strategy called FOPS and described in Table II). The converter frequency is fixed to $6.9 \mathrm{kHz}$ in order to set the extraction point to the initially measured MPP $\left(R_{\mathrm{S}}\left(t_{0}\right)=1 \mathrm{k} \Omega\right)$. The efficiency obtained for various MFC fluctuations is compared to the ones previously presented with MEES and MHES in Figure 5(d).

On the one hand, FOPS offers better performances than MEES for a MFC resistance range. Around the nominal MPP conditions ( $X$ axis at 1 ), the end-to-end efficiency values $\eta_{\text {Tот }}$ are approximately identical. However, when $R_{\mathrm{S}}$ gets more than twice larger ( $X$ axis at 2), FOPS offers slightly better results and almost reaches MHES performances. Despite the degradation of $\eta_{\text {EXTR }}$ when increasing $R_{\mathrm{S}}$ (Fig. 5(f)), $\eta_{\text {Tот }}$ with FOPS stays higher than $\eta_{\text {TOT }}$ with MEES because the switching losses induced by the increasing frequency have a drastic impact on $\eta_{\mathrm{CONV}}$. In the same way, when decreasing the MFC internal resistance by more than 10 ( $X$ axis at 0.1$)$, FOPS efficiency is better because $\eta_{\text {CONV }}$ is not impacted by the saturation issue encountered with MEES. Figure 5(f) clearly shows that $\eta_{\mathrm{CONV}}$ in the case of FOPS slightly increases when decreasing the resistance, while $\eta_{\text {CONV }}$ with MEES drastically drops.

On the other hand, FOPS offers approximately the same performances as MHES for MFC internal resistances close to the nominal one $(1 \mathrm{k} \Omega)$.

Therefore, the choice of a dynamic tracking (especially MEES) for $\mathrm{cm}^{2}$-electrode MFCs should not be systematic. Regarding the MFCs fluctuations range, setting a priori the converter operating points may increase the power delivered to the sensor, in addition to enhancing the system stability. Indeed, MEES and MHES require a control unit that may add instabilities as well as non-negligible losses in the system and may drastically reduce their end-to-end efficiency. FOPS offers then a satisfying trade-off.

\subsection{Evaluation of the Control Unit Power Budget}

With MEES and MHES, adding a control unit to the present circuit is necessary to adapt dynamically the frequency and should be considered with some power consumption. The power budget impacts MEES and MHES strategies instead of FOPS. Figure 5(d) pictures the efficiency figures for FOPS and allows quantifying the acceptable power budget $\Delta P_{\text {MEES }}$ (resp. $\Delta P_{\text {MHES }}$ ) of the control unit in order to keep higher performances using MEES (resp. MHES) compared to FOPS. This budget is calculated by subtracting the output power obtained with FOPS to the one obtained with MEES (resp. MHES) and averaging it over the MFC fluctuations range.

Over one day, the resistance $R_{\mathrm{DC}}$ varies between 0.5 to 2 times its nominal value ( $X$ axis between 0.5 and 2). Supposing a linear variation, the average budgets $\Delta P_{\text {MEES }}$ and $\Delta P_{\text {MHES }}$ are respectively $0.43 \mu \mathrm{W}$ and $1.65 \mu \mathrm{W}$, what reduces the range of adequate control circuits. These results reinforce the idea that setting a priori the converter parameters and avoiding a control unit may be a better solution for sub-mW benthic MFCs.

As an experimental validation of the FOPS accuracy for sub-mW MFCs, for one day, it has been shown that a

Table III. Comparison of experimental results.

\begin{tabular}{|c|c|c|c|c|c|c|c|}
\hline Specification & Erbay [7] & Wang [8] & Degrenne [9] & Zhang [10] & Thomas [21] & Alaraj [13] & This work \\
\hline MFC type & Wastewater & Wastewater & Wastewater & Wastewater & Compost & Water & Sediment \\
\hline$P_{\mathrm{MPP}}$ & $512 \mu \mathrm{W}$ & $5.21 \mathrm{~mW}^{a}$ & $10 \mathrm{~mW}$ & - & $2.5 \mathrm{~mW}$ & $1 \mathrm{~mW}$ & $90 \mu \mathrm{W}$ \\
\hline PMU & Boost in DCM & $\mathrm{CP}^{b}+$ Boost & Boost in DCM & $\mathrm{CP}^{b}+$ Boost & Flyback & Flyback in $\mathrm{CCM}$ & Flyback in DCM \\
\hline $\begin{array}{r}\text { Operating } \\
\text { strategy }\end{array}$ & MPP tracking ${ }^{c}$ & MPP tracking ${ }^{d}$ & FOPS & - & - & MPP tracking ${ }^{d}$ & FOPS \\
\hline Implementation & IC $0.5 \mu$ CMOS & Discrete & Discrete & $\begin{array}{l}\text { Discrete and } \\
\text { off-the-shelf }\end{array}$ & $\begin{array}{l}\text { Discrete and } \\
\text { off-the-shelf }\end{array}$ & Discrete & Discrete \\
\hline Output & $\begin{array}{l}\text { Wireless } \mathrm{T}^{\circ} \\
\text { sensor supplied } \\
\text { with } 2.5 \mathrm{~V}\end{array}$ & $\begin{array}{c}\text { 24F capacitance } \\
\text { charging from } \\
0 \mathrm{~V} \text { to } 2.5 \mathrm{~V}\end{array}$ & $\begin{array}{l}500 \Omega \text { resistance } \\
\text { supplied } \\
\text { with } 1.9 \mathrm{~V}^{a}\end{array}$ & $\begin{array}{l}\text { Humidity- } \mathrm{T}^{\circ} \\
\text { sensor supplied } \\
\text { with } 3.3 \mathrm{~V}\end{array}$ & $\begin{array}{l}\text { Wireless sensor } \\
\text { node supplied } \\
\text { with } 3.3 \mathrm{~V}\end{array}$ & $\begin{array}{l}1 F \text { capacitance } \\
\text { charging } \\
\text { from } 0 \mathrm{~V} \text { to } 2.2 \mathrm{~V}\end{array}$ & $\begin{array}{l}\text { Wireless } \\
\mathrm{T}^{\circ} \text {-acceleration } \\
\text { sensor supplied } \\
\text { with } 2.1 \mathrm{~V}\end{array}$ \\
\hline$\eta_{\text {Tот }}$ & $30 \%$ & $35.9 \%$ & $73 \%$ & $4.29 \%$ & $1 \%^{\mathrm{a}}$ & $50 \%$ & $72 \%$ \\
\hline
\end{tabular}

Notes: ${ }^{a}$ Extracted from data; ${ }^{b}$ Charge Pump; ${ }^{c}$ With setting the input voltage to a fraction of the open-circuit voltage of the MFC; ${ }^{d}$ Set the input voltage to the initially measure VMPP using a hysteresis controller. 
sensor ${ }^{20}$ powered with a $90 \mu \mathrm{W}$ MFC was able to measure and transmit the ambient temperature value every $4 \mathrm{~s}$ using the flyback and FOPS. The system end-to-end efficiency was $70 \%$, what is coherent with the results shown in Figure 5(b). Table III compares this result to prior art about harvesting energy from MFCs using different DC/DC converters. Present results are very competitive and comparable to the ones in Ref. [9] but for a power two orders of magnitude lower. The conversion topology as presented here and the design approach with fixed parameters offer then a solid candidate when MFC output power capability is very small.

As a perspective, we could also consider the sporadic operation of a control circuit in order to adapt the output power to its maximum maximorum, for instance once a day and leave the converter without tracking the rest of the day. The low duty cycle and frequency of the controller would drastically reduce its consumption. This idea fits the MFC characteristic since the MPP has been seen to be relatively stable in one day.

\section{CONCLUSION}

Benthic MFCs are promising energy harvesters for powering autonomously seafloor sensors in the long-term. Because of environmental fluctuations, their electrical behavior is likely to vary in time. Several studies focus on extracting the maximum power by dynamically adapting the MFC operating point to its maximum power point (MPP) called MEES. This paper questions the relevance of using MEES for sub-mW harvesters instead of (i) tracking the MPP at the converter output (MHES), or (ii) fixing the extraction point (FOPS).

First, we showed that MEES does not maximize the conversion efficiency of the converter used as electrical harvesting interface. In this way, when the power delivered by the MFC is decreased by two, MHES coherently allows reaching a higher end-to-end efficiency of $62 \%$, instead of $56 \%$ with MEES, while requiring a comparable control unit. The simulation showed that the decrease in the converter efficiency is mostly due to a saturation phenomenon occurring in the coupled inductances. Then, we showed that for MFC power close to the nominal one, $P_{\mathrm{MFC}}(90 \mu \mathrm{W})$, FOPS offers approximately the same performances as MEES and MHES and for larger MFC fluctuations $>2 P_{\mathrm{MFC}}$ and $\left.<0.1 P_{\mathrm{MFC}}\right)$, FOPS gets better than MEES. Eventually, the power budget of the control unit required with MEES and MHES were evaluated. Considering the power delivered by the MFC varies between 0.5 to 2 times its initial value (here $90 \mu \mathrm{W}$ ), the MEES and MHES budgets were calculated to be equal respectively to $0.3 \mu \mathrm{W}$ and $1.8 \mu \mathrm{W}$ restricting the range of possible circuits. This result clearly shows that for quite large MFC variations, MPPT strategies using a control circuit will be likely to induce lower performance than a converter with fixed parameters (FOPS), in addition to decrease the system complexity.

The experimental results were supported with simulation of the MFC electrical model associated with the converter losses' model. This new approach allows determining the major loss contributors e.g., the coupled inductance saturation) and may help in apprehending a design optimization (e.g., increasing the duty cycle).

\section{NOMENCLATURE}

\section{Abbreviations}

DCM Discontinuous Conduction Mode

FOPS Fixed Operating Point Strategy

MFC Microbial Fuel Cell

MEES Maximum Extracted Energy Strategy

MHES Maximum Harvested Energy Strategy

MPPT Maximum Power Point Tracking

\section{Symbols}

$D$ Converter's duty cycle

$f$ Converter's operating frequency

$\eta_{\text {CONV }}$ Conversion efficiency

$\eta_{\text {EXTR }}$ Extraction efficiency

$\eta_{\text {тот }} \quad$ End-to-end efficiency

\section{References}

1. IDTechEx: Market Research, Scouting and Events on Emerging Technologies, (2016). [Online]. Available: http://www.idtechex.com/ [Accessed: Oct. 22, 2018].

2. B. E. Logan, B. Hamelers, R. Rozendal, U. Schröder, J. Keller, S. Freguia, P. Aelterman, W. Verstraete, and K. Rabaey, Microbial fuel cells: Methodology and technology. Environmental Science and Technology 40, 5181 (2006).

3. T. Chailloux, A. Capitaine, B. Erable, and G. Pillonnet, Autonomous sensor node powered by $\mathrm{cm}$-scale benthic microbial fuel cell and low-cost and off-the-shelf components. Energy Harvesting and Systems 3, 205 (2016).

4. G. C. Premier, J. R. Kim, I. Michie, R. M. Dinsdale, and A. J. Guwy, Automatic control of load increases power and efficiency in a microbial fuel cell. J. Power Sources 196, 2013 (2011).

5. L. Woodward, M. Perrier, B. Srinivasan, R. P. Pinto, and B. Tartakovsky, Comparison of real-time methods for maximizing power output in microbial fuel cells. AIChE J. 56, 2742 (2010).

6. J.-D. Park and Z. Ren, Hysteresis controller based maximum power point tracking energy harvesting system for microbial fuel cells. J. Power Sources 205, 151 (2012).

7. C. Erbay, S. Carreon-Bautista, E. Sanchez-Sinencio, and A. Han, High performance monolithic power management system with dynamic maximum power point tracking for microbial fuel cells. Environ. Sci. Technol. 48, 13992 (2014).

8. H. Wang, J.-D. Park, and Z. Ren, Active energy harvesting from microbial fuel cells at the maximum power point without using resistors. Environ. Sci. Technol. 46, 5247 (2012).

9. N. Degrenne, F. Buret, F. Morel, S.-E. Adami, D. Labrousse, B. Allard, and A. Zaoui, Self-starting DC-DC boost converter for low-power and low-voltage microbial electric generators, Proceedings of the IEEE ECCE, 889 (2011), DOI: 10.1109/ECCE.2011.6063865

10. D. Zhang, F. Yang, T. Shimotori, K.-C. Wang, and Y. Huang, Performance evaluation of power management systems in microbial fuel 
cell-based energy harvesting applications for driving small electronic devices. J. Power Sources 217, 65 (2012).

11. J. An, J. Sim, Y. Feng, H.-S. Lee, Understanding energy loss in parallelly connected microbial fuel cells: Non-faradaic current. Bioresource Technology 203, 280 (2016).

12. L. Zhuang and S. Zhou, Substrate cross-conduction effect on the performance of serially connected microbial fuel cell stack. Electrochem. Commun. 11, 937 (2009).

13. M. Alaraj, Z. J. Ren, and J.-D. Park, Microbial fuel cell energy harvesting using synchronous flyback converter. J. Power Sources 247, 636 (2014).

14. A. Capitaine, G. Pillonnet, T. Chailloux, F. Khaled, O. Ondel, and B. Allard, Loss analysis of flyback in discontinuous conduction mode for sub-mW harvesting systems, Proceedings of the IEEE NEWCAS (2016), DOI: 10.1109/NEWCAS.2016.7604810

15. J. T. Babauta, M. Kerber, L. Hsu, A. Phipps, D. B. Chadwick, and Y. M. Arias-Thode, Scaling up benthic microbial fuel cells using flyback converters. J. Power Sources 395, 98 (2018).

16. F. Khaled, O. Ondel, and B. Allard, Optimal energy harvesting from serially connected microbial fuel cells. IEEE Transactions on Industrial Electronics 62, 3508 (2015).

17. Y. M. Arias-Thode, L. Hsu, G. Anderson, J. Babauta, R. Fransham, A. Obraztsova, G. Tukeman, and D. B. Chadwick, Demonstration of septistrand benthic microbial fuel cell powering a magnetometer for ship detection. J. Power Sources 356, 419 (2017).

18. R. W. Erickson and D. Maksimovic, Fundamentals of Power Electronics, Second Edition, Springer US, (2001), pp.108-117.

19. A. Capitaine, G. Pillonnet, T. Chailloux, A. Morel, and B. Allard, Impact of switching of the electrical harvesting interface on microbial fuel cell losses, Proceedings of the IEEE Sensors 1, (2017), DOI: $10.1109 /$ ICSENS.2017.8234189

20. M. Perez, S. Boisseau, P. Gasnier, J. Willemin, N. Pourchier, M. Geisler, and J. L. Reboud, Electret-based aeroelastic harvester and its self-starting battery-free power management circuit, Proceedings of the IEEE NEWCAS, (2015), DOI: 10.1109/NEWCAS.2015.7181988

21. Y. R. J. Thomas, M. Picot, A. Carer, O. Berder, O. Sentieys, and F. Barrière, A single sediment-microbial fuel cell powering a wireless telecommunication system. J. Power Sources 241, 703 (2013).

22. N. Degrenne, B. Allard, F. Buret, F. Morel, S. E. Adami, and D. Labrousse, Comparison of 3 self-starting step-up DC:DC converter topologies for harvesting energy from low-voltage and low-power microbial fuel cells, Proceedings of the 14th EPE (2011).

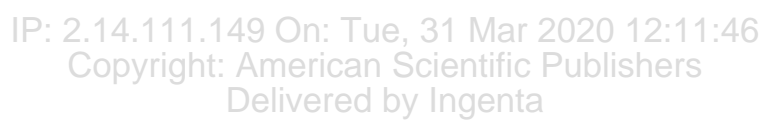

\section{Armande Capitaine}

Armande Capitaine was born in Brest, France, in 1991. She received her electrical engineering degree and her M.Sc degree in nanotechnologies from the National Polytechnic Institute (PHELMA-INP) in Grenoble in 2014. She followed international studies on nanotechnologies by working at Federal Institute of Technology in Lausanne (EPFL), Switzerland, and at the Politecnico di Torino, Italy. She received her Ph.D. in Electronics in 2017 from the University of Lyon, France. Her research project dealt with energy harvesting from benthic microbial fuel cells. Since 2018 she teaches Electronics in the French engineering school ENSEIRB MATMECA and works on electrochemical characterization of lithium-ion batteries in IMS laboratory in Talence, France.

\section{Gael Pillonnet}

Gael Pillonnet was born in Lyon, France, in 1981. He received his Master's degree in Electrical Engineering from CPE Lyon, France, in 2004, a PhD and habilitation degrees from INSA Lyon, France in 2007 and 2016, respectively. Following an early experience as analog designer in STMicroelectronics in 2008, he joined the University of Lyon in the Electrical Engineering department. During the 2011-12 academic year, he held a visiting researcher position at the University of California at Berkeley. Since 2013, he has been a full-time researcher at the CEA-LETI, a major French research institution. His research focuses on energy transfers in electronic devices such as power converter and amplifier, energy-recovery logic, mechatronics systems, scavenging interfaces.

\section{Bruno Allard}

Bruno Allard received the M.Sc. and Ph.D. degrees in engineering from INSA Lyon, in France, in 1989 and 1992, respectively. He is a Full Professor at the Electrical Engineering at INSA in Lyon. He is Director of Ampere-lab. He has led numerous industrial and academic projects. He is the author or coauthor of more than 100 papers in Transactions and journals and 300 international conference contributions. His research interests include the integration of power systems, either hybrid or monolithic, power semiconductor device modeling and characterization, power electronic system design and low-power monolithic converter design. 